\title{
Review
}

\section{Dementia and Oral Health: Is There A Connection?}

\author{
Suellan G.Yao, DMD'; James B. Fine, DMD ${ }^{2,3,4 *}$ \\ 'Private Practice, New York, NY, USA \\ ${ }^{2}$ Senior Academic Dean, Professor of Clinical Dentistry, Columbia University College of Dental Medicine, New York, NY, USA \\ ${ }^{3}$ Attending Dental Surgeon, Presbyterian Hospital Dental Service, New York, NY, USA \\ ${ }^{4}$ Private Practice Limited to Faculty Practice at Columbia University, New York, NY, USA

\section{"Corresponding author} \\ James B. Fine, DMD \\ Senior Academic Dean, Professor of Clinical Dentistry, Columbia University College of Dental Medicine, New York, NY, USA; Attending Dental Surgeon, \\ Presbyterian Hospital Dental Service, New York, NY, USA; Private Practice Limited to Faculty Practice at Columbia University, New York, NY, USA; \\ E-mail: jbfl@cumc.columbia.edu
}

\section{Article information}

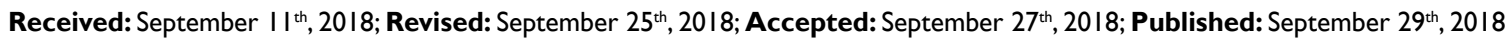

\section{Cite this article}

Yao SG, Fine JB. Dementia and oral health: Is there a connection? Dent Open J. 2018; 6(I): I-7. doi: 10.17/40/DOJ-6-I40

\section{ABSTRACT}

As the population ages, both Alzheimer's disease and periodontal disease may increase in incidence. Both do not have a cure and can affect quality of life. Research is being conducted to determine causes, treatments and potential relationship to each other. Proposed mechanisms to how they are related is via inflammation and/or bacteria. Several studies have addressed if dental treatment could improve cognitive function. However, further research is needed to further elucidate the relationship between both diseases. Common therapeutic approaches may help to manage both conditions, determine susceptibility and possibly prevention.

Keywords

Dementia/Alzheimer's disease; Periodontal disease; Cognitive health/function; Inflammation; Tooth loss; Masticatory function.

\section{INTRODUCTION /}

\section{Dementia and Inflammatory Periodontal Disease}

As the population ages, they will be at risk for more health problems. Two of those health issues are Alzheimer's disease (AD) and periodontal disease (PD). Both diseases do not have a cure and can affect the quality of life. Research is being conducted in order to determine causes, effective treatments and relationships to each other as well as to other health issues such as cardiovascular disease, diabetes and obesity. It is speculated that 1 in 85 people will be living with AD by 2050 and that approximately $5-20 \%$ of adults aged 65 years or older suffer from severe forms of PD. ${ }^{1}$ It is estimated that 47 million people are living with dementia in 2015 and this is projected to triple by $2050 .^{2}$

Often, dementia and $\mathrm{AD}$ are referred to interchangeably. Dementia is an umbrella terms for symptoms that affect the cognitive functions of the patient. These symptoms can include impaired memory, changes in thinking skills, decrease in focus and attention and poor judgement and reasoning skills. AD is a neu- rodegenerative disease and is the most common example of the group of diseases that manifest as dementia. It is characterized by progressive cognitive decline and memory loss with eventual complete loss of mental capabilities and death. ${ }^{3}$ It is categorized as either early or late/sporadic onset. Early onset is believed to be genetically determined, while late/sporadic onset is due to the interaction between genetics and environmental factors. It displays the formation of extracellular amyloid $\beta$-peptide (A $\beta P$ ) plaques and intraneuronal neurofibrillary tangles (NFTs) of hyperphosphorylated tau protein. This leads to the gradual loss of neuronal synapses and neuronal degeneration with loss of essential neurotransmitters. $^{4}$

There is no single medical test that will diagnose AD and only a definitive diagnosis can be made after death. However, doctors will look at medical history and do a physical, neurological and mental status exam. The Mini-Mental State Exam (MMSE) and Mini-Cog test are two commonly used assessments. During the MMSE, the healthcare provider asks a series of questions that test the range of everyday mental skills. The maximum score is 30 points. A score of 20-24 suggests mild dementia, 13-20 suggests 
moderate dementia and less than 12 points indicates severe dementia. On average, the MMSE score of a patient with AD decreased 2-4 points a year. With the mini-cog exam, the patient is required to do 2 tasks: 1) remember and then repeat the name of 3 common things a few minutes later and 2) draw the face of a clock with the 12 numbers in their correct positions and a time specified by the examiner. The US Food and Drug Administration has approved several computerized cognitive testing devices for marketing. They are: Cantab Mobile, Cognigram, Cognivue, Cognision and Automated Neuropsychological Assessment Metrics (ANAM) devices. Physicians use these computerized testing devices in addition to the MMSE and min-cog exams. Brain imaging such as magnetic resource imaging (MRI) and computed tomography (CT) can be used to rule out other conditions that can cause symptoms similar to $\mathrm{AD}$. While there have been genes identified that either increase the risk for $\mathrm{AD}$ or "deterministic" cause $\mathrm{AD}$, routine genetic testing is not recommended. ${ }^{5}$

PD is a chronic, inflammatory disease that is a result from the interplay between the bacterial infection and the host response in a susceptible patient. It affects the supporting structures of the tooth: connective tissue, alveolar bone and periodontal ligament (PDL) and results in bone loss, bleeding of the gingival tissues and mobility of teeth with eventual tooth loss. ${ }^{6}$ There is variability in the susceptibility of the patient which is reflected in the disease extent and severity. Porphyromonas gingivalis, Tannerella forsythia and Treponema denticola, which are known as the red complex are strongly associated with the diseased periodontal pocket. Kageyama et al, ${ }^{7}$ evaluated the relative abundance of subgingival plaque specific bacteria in the salivary microbiota and looked into the relationship between the abundance and severity of periodontal condition in patients with periodontitis. They found a good correlation between periodontal conditions and relative abundance of the subgingival plaque specific bacteria in the saliva. A systematic review including meta-analysis by Maldonado et al., 2018 assessed the potential differences in periodontal variables in patients with and without dementia. They found that patients with dementia displayed significantly worse clinical periodontal variables. This study emphasized the need for periodontal screening and treatment of elderly dementia patients.

\section{RELATIONSHIP BETWEEN DEMENTIA AND ORAL} HEALTH

There are possible proposed mechanisms as to how AD and PD are related, with inflammation being the link. One mechanism is via the increase of pro-inflammatory cytokines created by the periodontal pathogens and host response that eventually compromises the blood brain barrier and leads to priming or activation of the microglial cells in the cerebral regions. A second mechanism is due to the invasion of the brain by the microorganism from the dental plaque biofilm, which causes an inflammatory mechanism in the central nervous system which results in the cognitive impairment. ${ }^{8}$ Studies have been conducted to look further into these mechanisms. As there are not effective treatment in reversing dementia, it is important to identify modifiable risk factors in order to try to intervene and reduce incidence of disease. ${ }^{9}$
There are several reviews that look into the possible link between dementia and periodontal disease and tooth loss. One by Tonsekar et al, ${ }^{10}$ reviewed the literature on chronic periodontitis and tooth loss as risk factors for dementia or cognitive impairment. Possible mechanisms in which periodontal health can affect cognitive function is (1) it provides a peripheral source of proinflammatory cytokines, (2) nutritional habits change due to tooth loss and a diet low in antioxidants, vitamins $\mathrm{B}$ and $\mathrm{E}$ and high in unsaturated fats can contribute to dementia, and (3) the association is confounded by socioeconomic and environmental factors that can affect the prevalence and progression of both diseases. Tooth loss can lead to reduced masticatory function which can diminish cerebral blood flow and proprioception to the brain. However, they found the association to be inconclusive and that more randomized clinical trials need to be performed.

Aguayo et al, ${ }^{11}$ conducted a review focusing on the bacterial infection and $\mathrm{AD}$. They explore the relationship between brain bacterial infection and $\mathrm{AD}$ and on the existence of anti-microbial peptides having pore-forming properties that function similar to the pores formed by amyloid $-\beta$ in a variety of cell membranes. They believe that the control of biofilm mediated disease may be a potential preventive mechanism for AD.

Two other studies also looked at the relationship between tooth loss and memory loss. Oue et al, ${ }^{12}$ hypothesized that the molecular pathogenesis of $\mathrm{AD}$ is enhanced by molar tooth loss. The group studied mice and found that the experimental group showed impaired learning and memory abilities as compared to the control group. But total amyloid beta, A $\beta 40$ and $A \beta 42$ levels showed no significant intergroup difference. They concluded that molar tooth loss may cause neuronal loss in the hippocampus which may lead to memory loss, but that this is independent of the amyloid cascade. Kawahata et al, ${ }^{13}$ also used mice to study the hypothesis that permanent tooth loss of teeth at an early age affects cognitive function along with growth. They found that the loss of masticatory stimulation at an early age, which can cause chronic stress accelerates the aging process of hippocampal dependent cognition function and develops abnormal behavior of locomotor hyperactivation and lateralized behavior at an older age as a result in the dysfunction of the dopaminergic system.

Wu et al, ${ }^{14}$ conducted a systematic review of longitudinal studies examining the association between oral health and cognitive decline. They looked at 16 longitudinal studies. The studies had substantial design and assessment differences and the strength of the evidence is weak and findings were inconsistent. There needs to be a uniform set of cognitive assessments. Most studies used the Mini-Mental State Examination (MMSE), but better screens such as the Montreal Cognitive Assessment have become available. Many studies used standardized oral health examination protocols, such as the US National Institute of Dental Research protocol. But there needs to be more attention to calibration of dental assessment. It is unclear how or whether oral health and cognitive status are related. Additional research with greater agreement on how oral and cognitive status are assessed are needed to examine the linkage between the two. 
Noble et al, ${ }^{15}$ briefly reviewed the literature associating poor dental health with stroke with a focus on the relationship between poor dental health, particularly emphasizing periodontal health and cognitive impairment, dementia and AD. They felt that poor oral health, may be an unrecognized risk factor contributing to the development of cognitive impairment through dietary changes, malnutrition and systemic inflammatory response associated with increased risk of stroke and AD. Environmental and genetic risk factors and lack of attention to oral health care can lead to caries and periodontal disease which can lead to tooth loss. Tooth loss can lead to masticatory inefficiency and adverse diet and periodontal disease is related to the host inflammatory response and atherogenesis. Both can lead to cognitive impairment and in a circle lead to lack of oral health care. There should be more multidisciplinary research including translational, epidemiologic and possibly clinical treatment studies.

Ganesh et al, ${ }^{16}$ listed three plausible biological mechanisms linking periodontitis and AD: (1) metastatic spread of gram negative bacteria from the oral cavity to the brain, (2) neuronal injury trough transmigration across the blood brain barrier by inflammatory mediators that are produced in response to periodontitis as opposed to the periodontal pathogens invading the brain and (3) role of genetic polymorphisms in periodontitis and AD such as genetic polymorphisms of IL-1 and TNF- $\alpha$, both pro-inflammatory cytokines. However, if inflammation is to be established as a mediator, then it must be present in both diseases. There is no conclusive studies proving the bi-directional association between the two and the order in which they occur. Chronic periodontitis may be a modifiable risk factor for AD.
Gaur et $a 1,{ }^{17}$ presents a review that focuses on the plausible relationship between chronic periodontitis and $\mathrm{AD}$ and the dental implications of the latter. A bidirectional relationship may exist, where poor oral hygiene in AD patients leads to chronic periodontitis and eventual tooth loss and where poor oral hygiene causes chronic periodontitis and indirectly increases the risk for AD. The review explores the three mechanisms between $\mathrm{AD}$ and PD: 1) direct effects of periodontal pathogens, 2) indirect effects of the host response in terms of common inflammatory mediators and common genetic polymorphisms and 3) effects on vascular integrity that preceded the development of cerebrovascular pathology as seen in vascular dementia.

Singhrao et $a l,{ }^{18}$ felt that Porphyromonas gingivalis (p. gingivalis) may be the link between PD and AD. $\mathrm{p}$ gingivalis is a key periodontal pathogen in maintaining the inflammophilic microbiota of PD. They think that $\mathrm{p}$. gingivalis can access the central nervous system (CNS) during healthy stages but then in those individuals with inflammatory susceptibility traits, they will develop the progressive inflammatory component in the neurodegenerative disease process.

A case-control study by Aragón et al, ${ }^{19}$ made an oral health assessment of a group of Alzheimer's patients to look at implications of the characteristics of the disease and treatment of oral health. After controlling for age, they found that the group of Alzheimer's patient had worse oral health in terms of caries and periodontal disease, more mucosal lesions, such as cheilitis and candidiasis and worse saliva quality and quantity.

There are also multiple studies that explore the relation-

\begin{tabular}{|c|c|c|}
\hline Author & Study & Findings \\
\hline Aguayo et al ${ }^{19}$ & Review & $\begin{array}{l}\text { They explore the relationship between brain bacterial infection and AD and on the } \\
\text { existence of anti-microbial peptides having pore-forming properties that function } \\
\text { similar to the pores formed by amyloid - } \beta \text { in a variety of cell membranes. They } \\
\text { believe that the control of biofilm mediated disease may be a potential preventive } \\
\text { mechanism for AD. }\end{array}$ \\
\hline Maldonado et $\mathrm{al}^{20}$ & $\begin{array}{l}\text { Systematic Review including meta- } \\
\text { analysis }\end{array}$ & $\begin{array}{l}\text { Findings indicate that demented patients show significantly worse clinical periodontal } \\
\text { variable as compared to systemically healthy individuals supporting the putative link } \\
\text { between chronic periodontitis and dementia }\end{array}$ \\
\hline Aragón et al ${ }^{21}$ & Case-control study & $\begin{array}{c}\text { After adjustment of age, Alzheimer's patients had worse oral health, more mucosal } \\
\text { lesions and worse saliva quantity and quality }\end{array}$ \\
\hline Teixeira et $\mathrm{al}^{22}$ & Review & Findings point to inflammation playing an important role in periodontitis and AD. \\
\hline Takeuchi et a $\left.\right|^{23}$ & Prospective cohort & $\begin{array}{l}\text { It demonstrated an inverse association between number of remaining teeth and } \\
\text { risk of development of all-cause dementia and } A D \text {, which indicates that those with } \\
\text { greater tooth loss were at greater risk of onset of dementia. It did not reveal an } \\
\text { association with the development of vascular dementia. }\end{array}$ \\
\hline Lee et $\mathrm{al}^{24}$ & Prospective cohort study & $\begin{array}{l}\text { After adjustment for confounding factors, the risk of developing dementia was higher } \\
\text { for participants with periodontitis than for those without. This suggests that the risk } \\
\text { of dementia in elderly adults with periodontitis is significantly higher than in those } \\
\text { without periodontitis. }\end{array}$ \\
\hline Chen et $\mathrm{al}^{25}$ & $\begin{array}{l}\text { Retrospective matched cohort study } \\
\text { using the National Health Insurance } \\
\text { Research Database (NHIRD) of } \\
\text { Taiwan }\end{array}$ & $\begin{array}{l}\text { Findings demonstrate that a } 10 \text { year chronic periodontitis exposure was associated } \\
\text { with an increase in the risk of developing AD. }\end{array}$ \\
\hline
\end{tabular}




\begin{tabular}{|c|c|}
\hline Sochocka et al ${ }^{26}$ & $\begin{array}{l}\text { Test hypothesis that poor periodontal } \\
\text { health status may be associated with } \\
\text { cognitive impairment and dementia } \\
\text { via exacerbation of systemic inflam- } \\
\text { mation }\end{array}$ \\
\hline Ide et $\mathrm{al}^{27}$ & $\begin{array}{l}\text { Six month observational cohort } \\
\text { study }\end{array}$ \\
\hline Kamer et $\mathrm{al}^{28}$ & $\begin{array}{l}\text { Cross sectional study using positron } \\
\text { emission tomography (PE) amyloid } \\
\text { imaging }\end{array}$ \\
\hline
\end{tabular}

\begin{tabular}{|c|c|c|}
\hline Retrospective analysis of the pro- \\
Stewart et al ${ }^{29} \quad \begin{array}{c}\text { spective association between tooth } \\
\text { loss and dementia in the Prospective } \\
\text { Population Study of Women (PPSW) }\end{array}$
\end{tabular}

\begin{tabular}{|c|c|}
\hline $\begin{array}{l}\text { de Souza Rolim } \\
\text { et } \mathrm{al}^{30}\end{array}$ & $\begin{array}{l}\text { Descriptive not controlled open } \\
\text { study }\end{array}$ \\
\hline Noble et al ${ }^{31}$ & $\begin{array}{l}\text { Case cohort study studying serum } \\
\text { lgG to periodontal microbiota }\end{array}$ \\
\hline Stewart et al ${ }^{32}$ & $\begin{array}{l}\text { Investigation of the prospective as- } \\
\text { sociation between oral health status } \\
\text { and cognitive decline in the Health, } \\
\text { Aging and Body Composition (Health } \\
\text { ABC) study }\end{array}$ \\
\hline
\end{tabular}

Saito et $\mathrm{al}^{33} \quad$ Cross sectional study

\begin{tabular}{|cc} 
& Evaluated the relationship between \\
Park et a $^{34}$ & $\begin{array}{c}\text { cognitive impairment and tooth loss } \\
\text { in community dwelling adults aged } 50 \\
\text { years and up }\end{array}$ \\
\hline Minn et al & $\begin{array}{c}\text { Cohort based, cross-sectional, obser- } \\
\text { vational study }\end{array}$ \\
\hline Stein et al & $\begin{array}{c}\text { Examined serum antibody levels to } \\
\text { bacteria of periodontal disease in } \\
\text { patients who eventually converted to } \\
\text { AD compared to the antibody levels } \\
\text { of control patients using participants } \\
\text { in the Biologically Resilient Adults } \\
\text { in Neurological Studies (BRAINS) } \\
\text { research program }\end{array}$ \\
\hline
\end{tabular}

\begin{tabular}{|c|c|}
\hline Chen et $\mathrm{al}^{37}$ & Retrospective longitudinal study \\
\hline Kaye et $\mathrm{al}^{38}$ & $\begin{array}{l}\text { Prospective study of a cohort of } \\
\text { community dwelling men in the VA } \\
\text { Dental Longitudinal Study (DLS) }\end{array}$ \\
\hline
\end{tabular}

Okamoto et al ${ }^{39} \quad$ Cross sectional study

Stein et al ${ }^{36} \quad$ The Nun Study, a longitudinal study of aging and $A D$
They found that the presence of cognitive decline and additional source of proinflammatory mediators such as periodontal problems aggravate systemic inflammation. The comorbidity of these two disorders may increase cognitive impairment and neurodegenerative lesions and advance to dementia and $A D$

They did not find a clear relationship between severity of dementia and degree of periodontitis which may reflect the absence of patients with severe dementia in the study. It showed that $A D$ poor dental health, in particular, periodontitis, is associated with a marked increase in cognitive decline over a 6 month follow up period, independent to baseline cognitive state

Measure of periodontal disease were associated with amyloid accumulation in brain areas that are prone to amyloid accumulation in patients with $A D$ suggesting that periodontal disease may increase the risk for brain amyloid deposition

Dementia was associated with fewer teeth measured approximately 32, 20 and 8 years before its clinical onset with the first two of these associations remaining significant after adjustment for age; neither was significant after adjustment for age and education

After dental treatment, there was a reduction of orofacial pain and improvement of mandibular function and in periodontal condition in the patients with $A D$

Serum IgG levels to common periodontal microbiota are associated with risk for developing incident $A D$

Worse scores on oral health measures were associated with cognitive impairment but were confounded by education and race. Most were not associated with later cognitive decline except gingival inflammation which was the factor most strongly associated with impairment and the only factor predicting cognitive decline

Severe tooth loss ( 10 or less remaining teeth) was found to be significantly associated with poor cognitive function after adjusting for confounders. The number of teeth lost was significantly correlated with age, education level, current smoking status, positive history of diabetes and MMSE total score in this population

They found a significant association between cognitive impairment and tooth loss in adults aged 50 and up with no previous history of dementia or stroke. Also, that tooth loss is independently correlated with cognitive impairment after adjusting for confounding factors. It may be possible to use tooth loss as a prediction factor

they showed that severe tooth loss was associated with a high risk of white matter change/silent infarction and that tooth loss may be a predictor

Data demonstrates elevated antibodies to periodontal disease bacteria in patients years before cognitive impairment, suggesting that periodontal disease could potentially contribute to the risk of onset and/or progression of $A D$

The rate of tooth loss events did not differ significantly between participants with and without dementia. When dental treatment was provided, patients with dementia maintained their dentition as well as patients without dementia

The risk of cognitive decline in older men increases as more of their teeth are lost and periodontal disease progresses

The prevalence of low Mini Mental State Examination (MMSE) score was significantly increased in association with the decrease in the number of remaining teeth. After adjustment, a significant relationship between the decrease in the number of remaining teeth and a low MMSE score was observed. A decrease in the number of remaining teeth was associated with the risk of mild memory impairment

Findings suggest that a low number of tooth has an association with dementia late in life. But it is not clear if it is a causal relationship 
ship between AD and PD with inflammation being the key either directly or indirectly. They looked at antibody levels and tooth loss and periodontal status (Table 1).

\section{Dementia and Effects of Dental Therapy}

While many studies look into how to improve the oral health care of patients with dementia, a couple of studies looked into how dental treatment can improve cognitive function. Cerutti-Kopplin et $\mathrm{al},{ }^{40}$ examined the impact of the quality of denture on cognitive function in edentulous elderly patients wearing complete dentures. They did a cross sectional analysis of data that support the potential role of optimal functional quality of dentures in maintaining cognitive function which may be explained via the masticatory pathway. Previous animal studies ${ }^{41}$ have shown that impaired masticatory function can lead to impaired learning and spatial memory. Even in patients without teeth, masticatory sensory stimulus can be transmitted via the masticatory muscles, temporomandibular joint and mucous membrane to the hippocampus via the trigeminal nerve. A quality denture will provide better masticatory and mucous membrane stimulus. However, large cohort studies will need to be performed to further explore this treatment. A study by Fujii, ${ }^{42}$ investigated the improvement in patients with severe dementia after denture insertion. While the study only observed two patients, who were diagnosed with $\mathrm{AD}$, both showed improvement within weeks of denture delivery. While the reason why this treatment was successful is unclear, the author hypothesized that it was because positive signals from the oral cavity stimulated the brain via the trigeminal nerve. Obviously the small sample size makes it impossible to determine the treatment's effective ness. Both studies show the need to further investigate how dental treatment, such as dentures, can improve cognitive function.

\section{CONCLUSION}

This review tried to identify the potential link between AD and PD. Further research is still needed to elucidate the relationship between $\mathrm{AD}$ and $\mathrm{PD}$. As the world population ages, there are increasing number of older adults who may be susceptible and/ or develop both conditions. Common preventive and therapeutic approaches may help to manage both conditions, determine susceptibility and possibly prevention.

\section{CONFLICTS OF INTERESTS}

The authors declare that they have no conflicts of interest.

\section{REFERENCES}

1. Gaur S, Agnihotri R. Alzheimer's disease and chronic periodontitis: Is there an association? Geriatr Gerontol Int. 2015; 15: 391-404. doi: $10.1111 /$ ggi.12425

2. Baumgart M, Snyder HM, Carrillo MC, et al. Summary of the evidence on modifiable risk factors for cognitive decline and de- mentia: A population-based perspective. Alzheimers Dement. 2015; 11: 718-726. doi: 10.1016/j.jalz.2015.05.016

3. Chen CK, Wu YT, Chang YC. Association between chronic periodontitis and the risk of Alzheimer's disease: A retrospective, population-based, matched-cohort study. Alzheimers Res Ther. 2017; 9: 56. doi: 10.1186\%2Fs13195-017-0282-6

4. Abbayya K, Puthanakar NY, Naduwinmani S, Chidambar YS. Association between periodontitis and Alzheimer's disease. N Am J Med Sci. 2015; 7(6): 241-246. doi: 10.4103/1947-2714.159325

5. Alzheimer's Association. Website: www.alz.org. Accessed september 10, 2018.

6. AAP. Consensus report: chronic periodontitis. Annals of Periodontology. 1999; 4(1): 38. doi: 10.1902/annals.1999.4.1.38

7. Kageyama S, Takeshita T, Asakawa M, et al. Relative abundance of total subgingival plaque-specific bacteria in salivary microbiota reflects the overall periodontal condition in patients with periodontitis. PloS ONE. 2017: 12(4): e0174782. doi: 10.1371/journal. pone. 0174782

8. Maldonado A, Laugisch O, Bürgin W, Sculean A, Eick S. Clinical periodontal variables in patients with and without dementia - a systematic review and meta-analysis. Clin Oral Investig. 2018: 22; 2463-2474. doi: 10.1007/s00784-018-2523-x

9. Kaye EK, Valencia A, Baba N, et al. Tooth loss and periodontal disease predict poor cognitive function in older men. J Am Geriatr Soc. 2010; 58(4): 713-718. doi: 10.1111/j.1532-5415.2010.02788.x

10. Teixeira FB, Saito MT, Matheus FC, et al. Periodontitis and Alzheimer's disease: A possible comorbidity between oral chronic inflammatory condition and neuroinflammation. Front Aging Neurosci. 2017: 9; 327. doi: 10.3389\%2Ffnagi.2017.00327

11. Tonsekar PP, Jiang SS, Yue G. Periodontal disease, tooth loss and dementia: Is there a link? A systematic review. Gerodontology. 2017; 1-13. doi: 10.1111/ger.12261

12. Aguayo S, Schuh CMAP, Vicente B, Aguayo LG. Association between Alzheimer's disease and oral and gut microbiota: Are pore forming proteins the missing link? J Alsheimer's Dis. 2018; 65(1): 29-46. doi: 10.3233/JAD-180319

13. Oue H, Miyamoto Y, Okada S, et al. Tooth loss induces memory impairment and neuronal cell loss in APP transgenic mice. Behav Brain Res. 2013; (252): 318-325. doi: 10.1016/j.bbr.2013.06.015

14. Kawahata M, Ono Y, Ohno A, et al. Loss of molars early in life develops behavioral lateralization and impairs hippocampus-dependent recognition memory. BMC Neurosci. 2014; 15: 4. doi: $10.1186 \% 2 \mathrm{~F} 1471-2202-15-4$ 
15. Wu B, Fillenbaum GG, Plassman BL, Guo L. Association between oral health and cognitive status: A systematic review. $J A m$ Geriatr Soc. 2016; 64: 739-751. doi: 10.1111/jgs.14036

16. Noble JM, Scarmeas N, Papapanou PN. Poor oral health as a chronic, potentially modifiable dementia risk factor: Review of the literature. Curr Neurol Neurosii Rep. 2013; 13(10): 384. doi: $10.1007 / \mathrm{s} 11910-013-0384-\mathrm{x}$

17. Ganesh P, Karthikeyan R, Muthukumaraswamy A, Anand J. A potential role of periodontal inflammation in Alzheimer's disease: A review. Oral Health Prev Dent. 2017; 15: 7-12. doi: 10.3290/j. ohpd.a37708

18. Singhrao SK, Harding A, Poole Sophie, Kesavalu L, Crean SJ. Porphyromonas gingivalis periodontal infection and its putative links with Alzheimer's disease. Mediators Inflamm. 2015; 2015: 137357. doi: 10.1155/2015/137357

19. Aragón F, Zea-Sevilla MA, Montero J, et al. Oral health in Alzheimer's disease: A multicenter case-control study. Clin Oral Investig. 2018. doi: 10.1007/s00784-018-2396-z

20. Takeuchi K, Ohara T, Furuta M, et al. Tooth loss and risk of dementia in the community: The Hisayama study. J Am Geriatr Soc. 2017; 65: e95-e100. doi: 10.1111/jgs.14791

21. Lee YT, Lee HC, Hu CJ, et al. Periodontitis as a modifiable risk factor for dementia: A nationwide population-based cohort study. J Am Geriatr Soc. 2017; 65(2): 301-305. doi: 10.1111/jgs.14449

22. Chen CK, Wu YT, Chang YC. Association between chronic periodontitis and the risk of Alzheimer's disease: A retrospective, population-based, matched-cohort study. Alzheimers Res Ther. 2017; 9(1): 56. doi: 10.1186/s13195-017-0282-6

23. Sochocha M, Sobczyński M, Sender-Janeczek A, et al. Association between periodontal health status and cognitive abilities. The role of cytokine profile and systemic inflammation. Curr Alzheimer Res. 2017; 14(9): 978-990. doi: 10.2174/156720501466617031616 3340

24. Ide M, Harris M, Stevens A, et al. Periodontitis and cognitive decline in Alzheimer's disease. PLoS ONE. 2016; 11(3): e0151081. doi: 10.1371/journal.pone.0151081

25. Kamer AR, Pirraglia E, Rsui W, et al. Periodontal disease associates with higher brain amyloid load in normal elderly. Neurobiol Aging. 2015; 36(2): 627-633. doi: 10.1016/j.neurobiolaging.2014.10.038

26. Stewart R, Stenman U, Hakeberg M, et al. Association between oral health and risk of dementia in a 37 year follow-up study: The prospective population study of women in Gothenburg. $J \mathrm{Am} \mathrm{Ge-}$ riatr Soc. 2015; 63: 100-105. doi: 10.1111/jgs.13194
27. Rolim Tde S, Fabri GM, Nitrini R, et al. Evaluation of patients with Alzheimer's disease before and after dental treatment. Arq Neuropsiquiatr. 2014; 72(12): 919-924. doi: 10.1590/0004282X20140140

28. Noble JM, Scarmeas N, Celenti RS, et al. Serum IgG antibody levels to periodontal microbiota are associated with incident Alzheimer disease. PLoS ONE. 2014; 9(12): e114959. doi: 10.1371/ journal.pone.0114959

29. Stewart R, Weyant RJ, Garcia ME, et al. Adverse oral health and cognitive decline: The health, aging and body composition study. $J$ Am Geriatr Soc. 2013; 61(2): 177-184. doi: 10.1111/jgs.12094

30. Saito Y, Sugawara N, Yasui-Furukori N, et al. Cognitive function and number of teeth in a community-dwelling population in Japan. Ann Gen Psychiatry. 2013; 12(1): 20. doi: 10.1186/1744859X-12-20

31. Park H, Suk SH, Cheong JS, et al. Tooth loss may predict poor cognitive function in community-dwelling adults without dementia or stroke: The PRESENT Project. J Korean Med Sci. 2013; 28: 1518 1521. doi: $10.3346 \% 2 F j k m s .2013 .28 .10 .1518$

32. Minn YK, Suk SH, Park H, et al. Tooth loss is associated with brain white matter changes and silent infarction among adults with dementia and stroke. J Korean Men Sci. 2013; 28: 929-933. doi: 10.3346/jkms.2013.28.6.929

33. Stein PS, Steffen MJ, Smith C, et al. Serum antibodies to periodontal pathogens are a risk factor for Alzheimer's disease. Alžbeimers Dement. 2012; 8(3): 196-203. doi: 10.1016/j.jalz.2011.04.006

34. Chen X, Shuman SK, Hodges JS, Gatewood LC, Xu J. Patterns of tooth loss in older adults with and without dementia: A retrospective study based on a Minnesota cohort. J Am Geriatr Soc. 2010; 58: 2300-2307. doi: 10.1111/j.1532-5415.2010.03192.x

35. Kaye EK, Valencia A, Baba N, et al. Tooth loss and periodontal disease predict poor cognitive function in older men. I Am Geriatr Soc. 2010; 58(4): 713-718. doi: 10.1111/j.1532-5415.2010.02788.x

36. Okamoto N, Morikawa M, Okamoto K, et al. Relationship of tooth loss to mild memory impairment and cognitive impairment: findings from the fujiwara-kyo study. Behav Brain Funct. 2010; 6: 77. doi: 10.1186/1744-9081-6-77

37. Stein PS, Desrosiers M, Donegan SJ, Yepes JF, Kryscio RJ. Tooth loss, dementia and neuropathology in the Nun study. $J A m$ Dent Assoc. 2007; 138(10): 1314-1322.

38. Cerutti-Kopplin D, Emani D, Hilgert JB, Hugo FN, Padilha DMP. Cognitive status of edentate elders wearing complete denture: does quality of denture matter? J Am Dent Assoc. 2015; 43: 1071-1075. 
39. Onozuka MWK, Mirbod SM, Ozono S, Nishiyama K, Karasawa $\mathrm{N}$ and Nagatsu I. Reduced mastication stimulate impairment of spatial memory and degeneration of hippocampal neurons in aged SAMP8 mice. Brain Res. 1999; 826(1): 148-153.

40. Maeda NKT, Osawa K, Yamamoto Y, et al. Effects of longterm intake of a fine-grained diet on the mouse masseter muscle. Acta Anat (Basel). 1987; 128(4): 326-333.
41. Watanabe K, Ozono S, Mishiyama K, et al. The molarless condition in aged SAMP8 mice attenuates hippocampal Fos induction linked to water maze performance. Behav Brain Res. 2002; 128(1): $19-25$.

42. Fujii Y. Two cases of severe dementia showing dramatic improvement after denture placement. Advances in Alzheimer's Disease. 2016; 5: 46-52. doi: 10.4236/aad.2016.52004 